\title{
A sheet metal necking formability diagram for nonlinear strain paths
}

\section{Christiansen, Peter; Jensen, Mikkel Ravn Boye; Winther, Grethe}

Published in:

Proceedings of the Institution of Mechanical Engineers, Part L: Journal of Materials: Design and Applications

Link to article, DOI:

$10.1177 / 1464420717739644$

Publication date:

2019

Document Version

Peer reviewed version

Link back to DTU Orbit

Citation (APA):

Christiansen, P., Jensen, M. R. B., \& Winther, G. (2019). A sheet metal necking formability diagram for nonlinear strain paths. Proceedings of the Institution of Mechanical Engineers, Part L: Journal of Materials: Design and Applications, 233(7), 1287-1294. https://doi.org/10.1177/1464420717739644

\section{General rights}

Copyright and moral rights for the publications made accessible in the public portal are retained by the authors and/or other copyright owners and it is a condition of accessing publications that users recognise and abide by the legal requirements associated with these rights.

- Users may download and print one copy of any publication from the public portal for the purpose of private study or research.

- You may not further distribute the material or use it for any profit-making activity or commercial gain

- You may freely distribute the URL identifying the publication in the public portal 
Original article

Corresponding author info

Corresponding author:

Peter Christiansen, Technical University of Denmark, Produktionstorvet, 2800 Kgs. Lyngby, Denmark

Email: petc@mek.dtu.dk

\title{
A sheet metal necking formability diagram for nonlinear strain paths
}

Peter Christiansen ${ }^{1}$, Mikkel R. B. Jensen ${ }^{1}$ and Grethe Winther ${ }^{1}$

${ }^{1}$ Technical University of Denmark, Kgs. Lyngby, Denmark

\begin{abstract}
A new procedure for drawing forming limit curves is suggested. The theoretical basis for computing the forming limit curve due to diffuse necking, for nonlinear strain paths, is derived. The theoretically determined forming limit curve is compared with experimentally determined forming limits for both linear and bilinear strain paths. Reasonable agreement is observed. The procedure can also be utilized for nonlinear strain paths in general.
\end{abstract}

Keywords: Sheet metal forming, formability diagram, necking instability, nonlinear strain path 


\section{Introduction}

Sheet metal forming is a common manufacturing process. Products produced are for instance beverage cans, car body parts, lamps and various covers. The production methods are typically deep drawing, ironing, stamping and cutting.

When performing a stamping operation of a complex part, cracks due to excessive deformation may occur in the deforming sheet. These cracks are undesirable and should be avoided. To avoid an expensive trial-and-error process of producing a large number of stamping tools until achieving feasible forming conditions without sheet fracture, it is desirable during the tool design phase to predict, whether excessive deformation leading to necking and subsequent crack formation will occur.

Keeler ${ }^{1}$ introduced the usage of forming limit diagrams (FLD) for stretch forming of metal sheets. This was expanded to the drawing region by Goodwin ${ }^{2}$. Both utilized approximately linear strain paths to determine the forming limit curve (FLC).

A schematic of a forming limit diagram for an isotropic metal sheet can be seen in Figure 1. The diagram has the maximum $\left(\varepsilon_{\max }\right)$ and minimum $\left(\varepsilon_{\min }\right)$ principal, in-plane plastic strains of the sheet on the axes. If $\varepsilon_{\min }<0$, the deformation is denoted "drawing". If $\varepsilon_{\min }>0$, the deformation is denoted "stretching". The schematic forming limit curve is drawn for strain combinations ranging from uniaxial tension $\left(\varepsilon_{\max }=-2 \varepsilon_{\min }\right)$ to balanced biaxial stretch $\left(\varepsilon_{\max }=\varepsilon_{\min }\right)$.

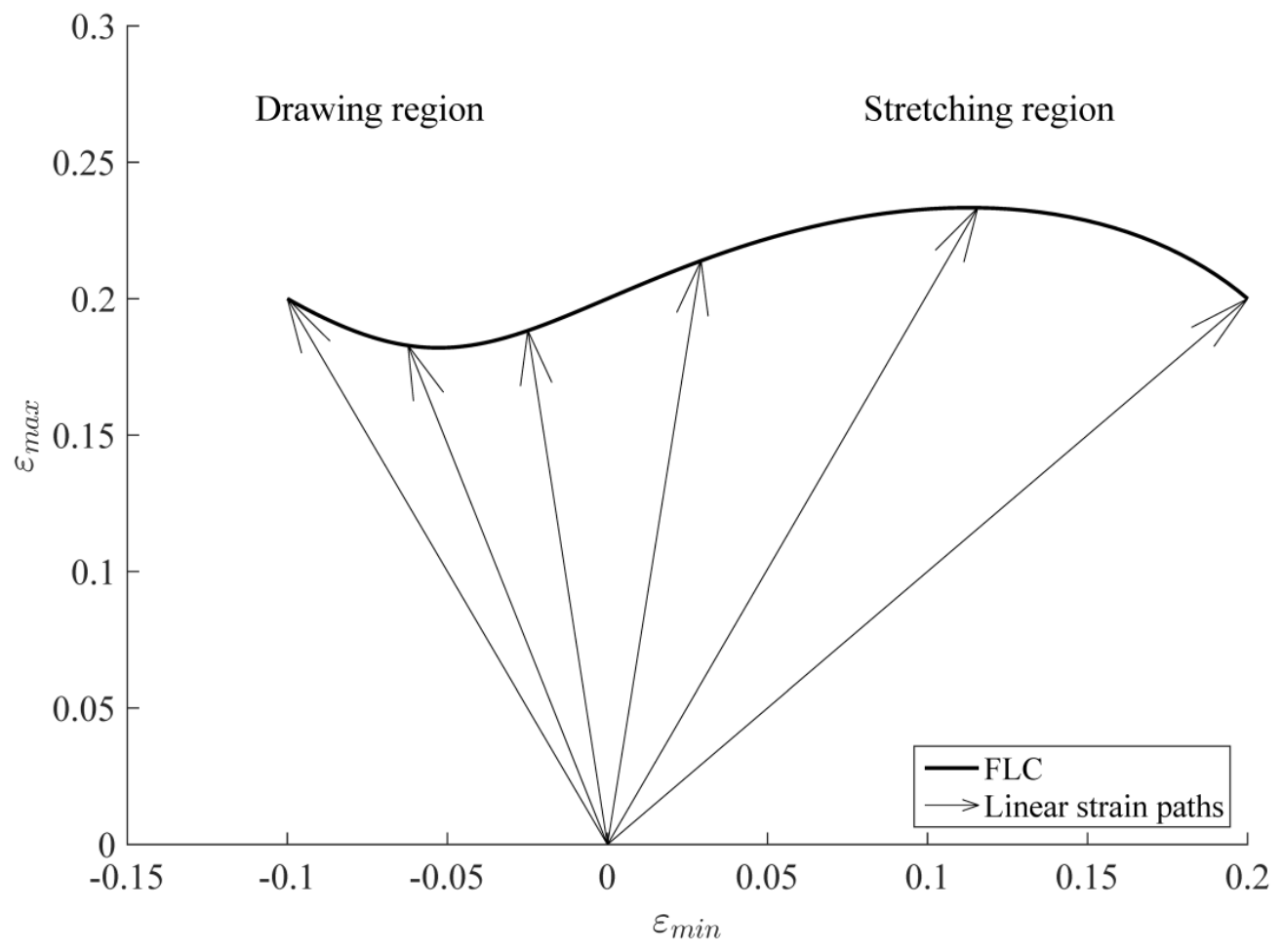

Figure 1. Forming limit diagram. 
The forming limit curve may be determined experimentally by for instance Marciniak ${ }^{3}$ or Nakazima ${ }^{4}$ tests. The first test utilizes deformation of cut-out blanks by a flat punch while the other uses a spherical punch. The strains at fracture are determined by a circle grid applied typically by etching on the sheet before deformation or by the use of digital image correlation (DIC) systems. Further information regarding standards for determining forming limit diagrams can be found in the ISO standard ${ }^{5}$.

A critique against forming limit diagrams based on linear strain paths was raised by Müschenborn and Sonne ${ }^{6}$, who found that the forming limit curve does not have a constant location in the forming limit diagram but is strain path dependent. They performed a number of experiments involving bi-linear strain paths and concluded that only the final strain path is determining the formability limit. Hence for a bilinear strain path, the forming limit curve needs to be redetermined after the first deformation. This can be seen schematically in Figure 2.

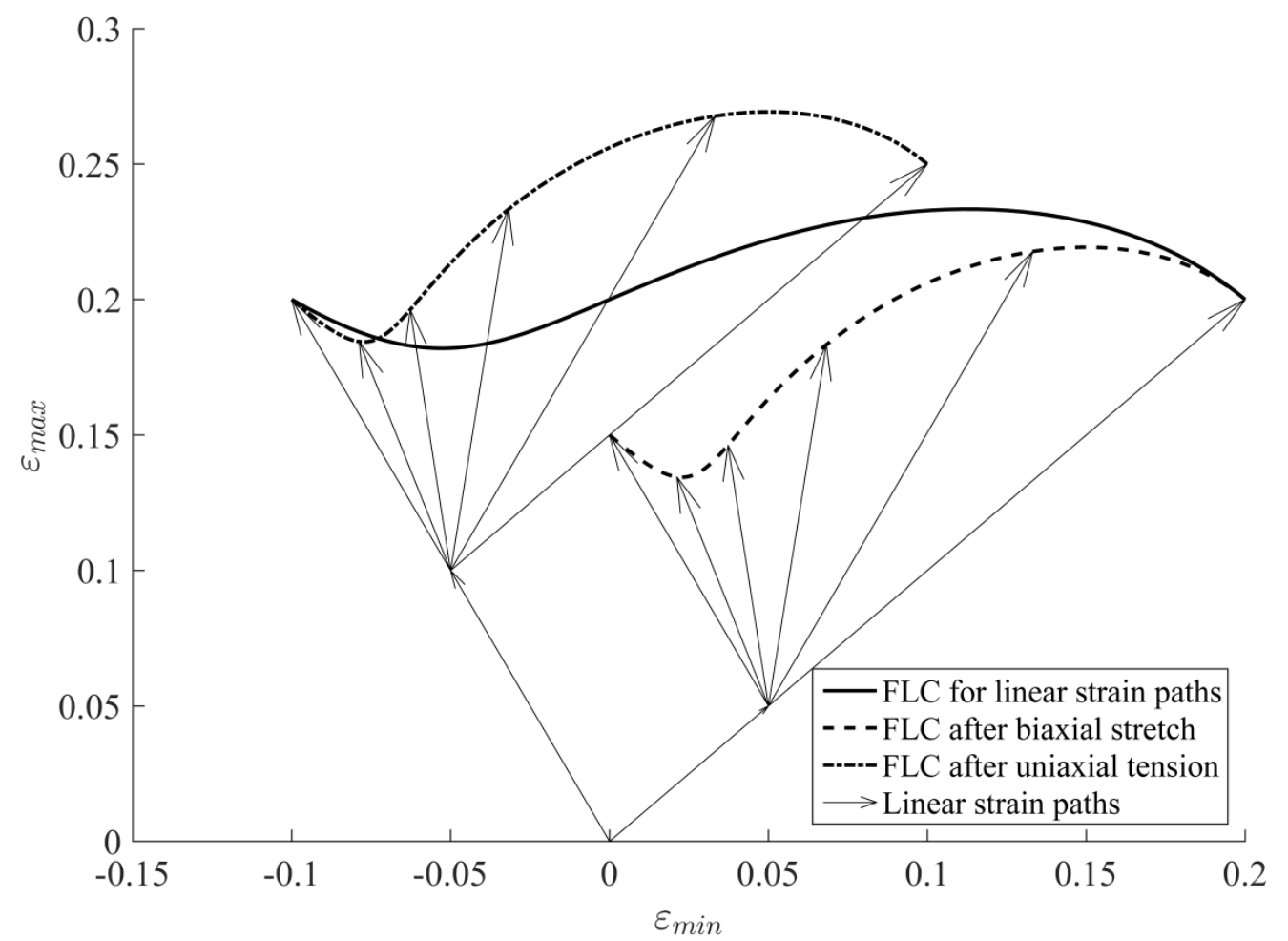

Figure 2. Forming limit diagram after deformation to $\bar{\varepsilon}_{1}=0.1$ either by uniaxial tension or biaxial stretching.

Figure 2 shows the forming limit curve for linear strain paths for an initially undeformed sheet, a forming limit curve after uniaxial tension to an equivalent plastic strain $\bar{\varepsilon}_{1}=0.1$ and a forming limit curve after biaxial stretching to $\bar{\varepsilon}_{1}=0.1$. It can be seen that a new formability curve needs to be determined for each possible strain path, thus limiting the usefulness of the method to design sheet metal forming processes with nonlinear strain paths such as for instance two-stage forming processes. As an alternative to the strainbased formability diagram Yoon and Stoughton ${ }^{7}$ suggested to use a polar strain diagram. 
Arrieux ${ }^{8}$ suggested using a stress based forming limit diagram based on the two in-plane principal stresses. A review of stress based forming limit diagrams can be found in Stoughton and $\mathrm{Zhu}^{9}$. A thorough mathematical derivation of stress-based forming limit diagrams where presented by Stoughton and Yoon ${ }^{10}$, who also suggested to include a formability limit due to cracking and not only necking. Measurements of stress for many deformation methods are difficult, but stress based forming limit diagrams may be determined by means of, for example, cruciform samples or diffraction of neutrons (Upadhyay et al. ${ }^{11}$ ) or X-rays (Iadicola et al. ${ }^{12}$ ) to measure the lattice strain induced in the metal. Although giving reasonable agreement with experiments, a critique to applying stress based forming limit diagrams is that they do not immediately present to the user how a metal forming operation should be performed in order to yield largest plastic strains, which indicates largest formability of the metal. This is of importance since the formability of the metal should be exploited as much as possible. Also from a strength point of view it is beneficial if the formed component has undergone plastic deformation to yield larger work hardening. The alternative to work hardening is a time and cost consuming thermal hardening, which is furthermore not possible for all materials, including the commercially pure aluminium alloy of the present paper.

It is the aim and scope of this paper to outline and alternative forming limit curve determination for bilinear strain paths. Two different forming limit curves are usually considered: necking and fracture. Necking is the onset of strain localization, which may be either diffusive or local. The paper focuses on the onset of diffuse necking.

\section{Diffuse instability theory}

A plane stress sheet metal forming operation is considered. The sheet is assumed to follow Hill's ${ }^{13} 1948$ yield surface and diffuse instability occurs due to Swift's ${ }^{14}$ criterion. The relationship $s$ between the two principal, in-plane maximum $\left(d \varepsilon_{\max }\right)$ and minimum $\left(d \varepsilon_{\min }\right)$ strain increments are

$$
s=\frac{d \varepsilon_{\min }}{d \varepsilon_{\max }}
$$

The stress ratio $x$ between the two in-plane principal maximum $\sigma_{\max }$ and minimum stresses $\sigma_{\min }$ are

$$
x=\frac{\sigma_{\min }}{\sigma_{\max }}=\frac{(1+R) s+R}{(1+R)+R s}
$$

The degree of anisotropy is described by the Lankford coefficient ${ }^{15} R=\varepsilon_{w} / \varepsilon_{t}$, where $\varepsilon_{w}$ is the width strain and $\varepsilon_{t}$ is the thickness strain of a uniaxial tensile test. The Lankford coefficient is usually determined at 0,45 and 90 degrees to the rolling direction of the sheet. The equivalent stress $\sigma_{e q}$ is given by

$$
\sigma_{e q}=\sqrt{\sigma_{\text {max }}^{2}+\sigma_{\text {min }}^{2}-\frac{2 R}{1+R} \sigma_{\text {max }} \sigma_{\text {min }}}
$$


The equivalent plastic strain increment $d \bar{\varepsilon}_{e q}$ is then expressed as

$$
d \bar{\varepsilon}_{e q}=\frac{1+R}{\sqrt{1+2 R}} \sqrt{d \varepsilon_{\max }^{2}+d \varepsilon_{\min }^{2}+\frac{2 R}{1+R} d \varepsilon_{\max } d \varepsilon_{\min }}
$$

If the metals flow stress $\sigma_{f}$ can be described by Swift hardening $\sigma_{f}=C\left(\varepsilon_{0}+\bar{\varepsilon}_{e q}\right)^{n}$, where $C$ is the strength coefficient, $\varepsilon_{0}$ is the prestrain, $\bar{\varepsilon}_{e q}$ is the equivalent plastic strain and $n$ is the strain hardening exponent, the criterion for diffuse instability is given by Danckert and Wanheim ${ }^{16}$ as

$$
\bar{\varepsilon}_{e q, i n s t}=Z n-\varepsilon_{0}
$$

where $Z$ is the subtangent

$$
Z=\frac{4\left(1-x+x^{2}\right)^{\frac{3}{2}}}{4-3 x-3 x^{2}+4 x^{3}}
$$

Based on the above equations it is possible to generate a theoretical forming limit curve as seen in Figure 1. If a bilinear strain path is encountered, a new formability curve based on the intermediate equivalent plastic strain $\bar{\varepsilon}_{1}$ can be computed and parallel-shifted to the intermediate location in the forming limit diagram. This is seen in Figure 2. A simplified approach eliminating the need for parallel-shifting the forming limit curve is suggested next.

\section{A new forming limit diagram for nonlinear strain paths}

A two-stage forming operation is seen schematically in Figure 3.

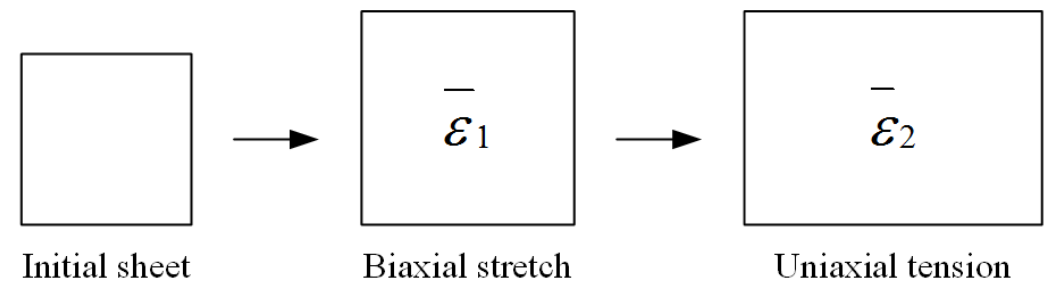

Figure 3. Two-stage sheet metal forming process.

Figure 3 shows a sheet being biaxially stretched to the equivalent strain $\bar{\varepsilon}_{1}$ and then drawn in uniaxial tension to the equivalent strain $\bar{\varepsilon}_{2}$, at which diffusive necking starts to occur. A traditional forming limit diagram for this deformation can be seen Figure 2. 
The new approach for a formability diagram consists of modifying equation [5] to

$$
\bar{\varepsilon}_{e q, i n s t}=Z n-\varepsilon_{0}-\bar{\varepsilon}_{1}
$$

The approach then consists of computing the forming limit curve for various, different values of $\bar{\varepsilon}_{1}$ and draw the curve with respect to origin in the forming limit diagram. An example can be seen in Figure 4.

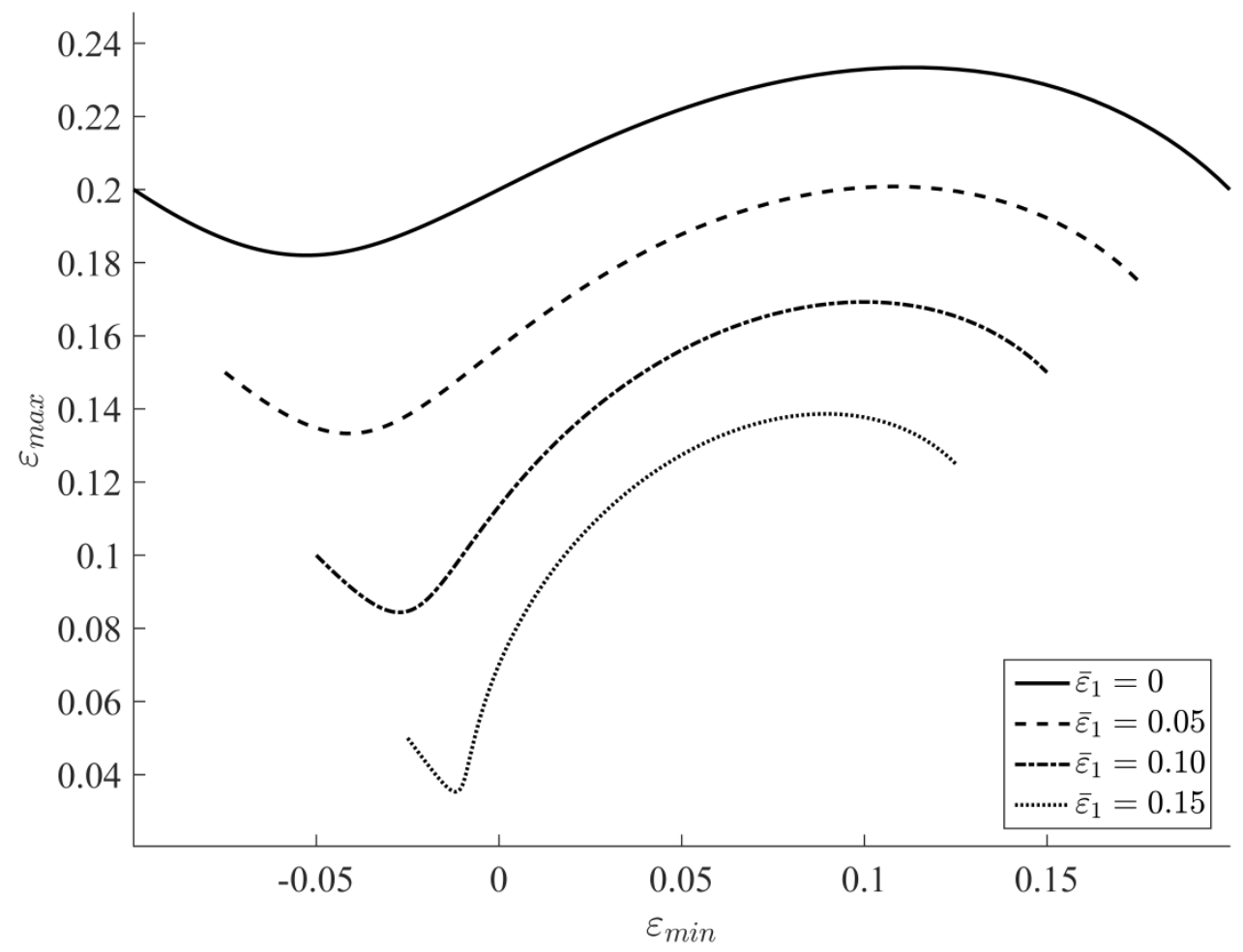

Figure 4. Forming limit curves corresponding to different values of equivalent strain $\overline{\varepsilon_{1}}$ in the first forming operation.

Figure 4 shows forming limit curves for an isotropic metal sheet with $n=0.2$ and $\varepsilon_{0}=0$ having been deformed to various levels of equivalent plastic strain $\bar{\varepsilon}_{1}$ in the first deformation operation. The curves illustrate the remaining formability before diffusive necking occurs in the second deformation operation. The forming limit diagram gives an immediate impression of how formability is influenced by the strain from a previous forming operation. It can be seen that the remaining amount of straining before diffusive necking occurs is reduced more in the drawing region than in the stretching region. This is in qualitative agreement with Müschenborn and Sonne $^{6}$ who found that enhanced formability is achieved if the first deformation operation is a drawing operation followed by a stretching operation. Decreased formability was noticed if the opposite order of the two operations was applied. 


\section{Experiments}

A number of experiments were performed to support the suggested, new procedure. First the stress-strain behaviour and Lankford coefficient for the metal were determined. The same experiments yielded a linear strain path to diffuse necking.

Samples were also first rolled and then loaded in uniaxial tension until necking, thus giving a nonlinear strain path.

Blanks were also biaxially stretched and small dog bone shaped samples were cut out to be elongated in uniaxial tension thereby also giving rise to a nonlinear strain path.

\section{Workpiece material characterisation}

The experiments are performed using aluminium 1050-O sheets of $1 \mathrm{~mm}$ thickness in the "as-received" condition.

The experiments were performed on a $100 \mathrm{kN}$ Amsler universal testing machine equipped with a $50 \mathrm{kN}$ HBM Z4 force transducer. Elongation of the samples was measured using a Trans-Tek 603-005 length extensometer and the transverse contraction was measured using a Trans-Tek 351-000 length extensometer. Data acquisition was performed using a custommade LabView program. The tensile test specimens were rectangular strips $250 \mathrm{~mm}$ long and $20 \mathrm{~mm}$ wide, clamped in each end by jaws during the experiment. The deformation was measured by the extensometers in the middle of the specimen, where homogeneous deformation prevails. Due to the slow motion of the press crosshead, rate effects are considered negligible.

Three uniaxial tensile tests were performed in the rolling direction to achieve the average flow stress curve $\sigma_{f}=128\left(0.004+\bar{\varepsilon}_{e q}\right)^{0.207}[\mathrm{MPa}]$, which can be seen in Figure 5 . The average Lankford coefficient $R=1.42$ was also determined for the rolling direction. The mechanical properties were not determined at 45 and 90 degrees to the rolling direction since the final strain path of all the experiments was always tension in the rolling direction. 


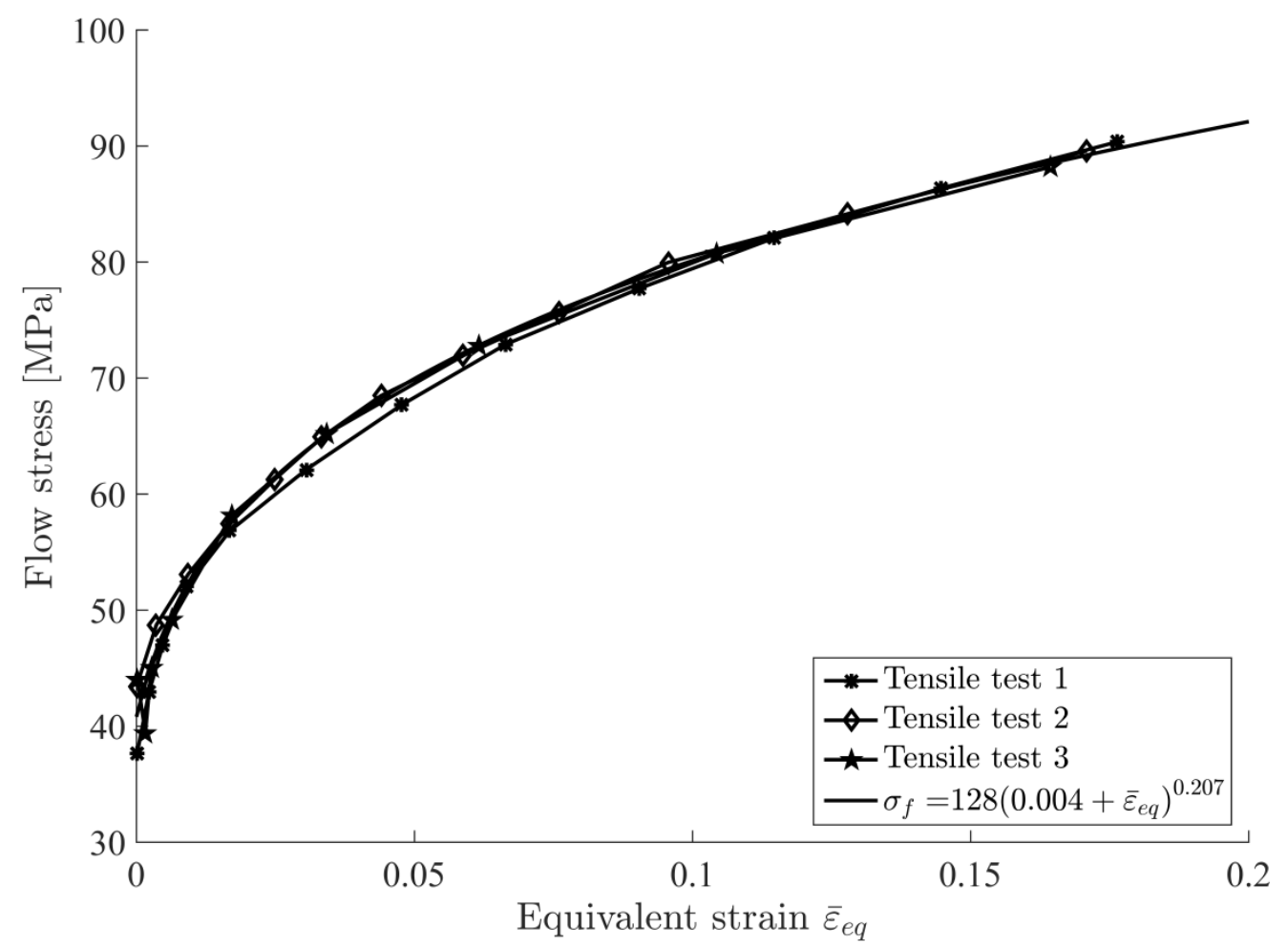

Figure 5. Uniaxial tensile tests and average flow stress curve in the rolling direction of the sheet.

\section{Forming limit curve experiments}

Four sets of experiments were performed: uniaxial tension until necking, rolling followed by uniaxial tension until necking and biaxial stretching, to two different strain levels, followed by uniaxial tension until necking. An overview of the experiments can be seen in Table 1.

Table 1. Overview of experiments.

\begin{tabular}{|l|l|}
\hline Experiment & Strains in forming operation 1 \\
\hline Uniaxial tension & $\varepsilon_{\min }=0, \varepsilon_{\max }=0, \bar{\varepsilon}_{1}=0$ \\
\hline Rolling followed by uniaxial tension & $\varepsilon_{\min }=0, \varepsilon_{\max }=0.14, \bar{\varepsilon}_{1}=0.17$ \\
\hline Biaxial stretching 1 followed by uniaxial tension & $\varepsilon_{\min }=0.04, \varepsilon_{\max }=0.04, \bar{\varepsilon}_{1}=0.09$ \\
\hline Biaxial stretching 2 followed by uniaxial tension & $\varepsilon_{\min }=0.13, \varepsilon_{\max }=0.14, \bar{\varepsilon}_{1}=0.29$ \\
\hline
\end{tabular}

\section{Uniaxial tension}

The aforementioned strips used to obtain the flow stress curve were also used to obtain the strains at necking in uniaxial tension. The strains were determined from the measured elongation and width contraction during the experiments. A specimen after fracture can be seen in Figure 6b.

Rolling followed by uniaxial tension 
Rectangular strips of $250 \mathrm{~mm}$ length and $20 \mathrm{~mm}$ width were rolled using a $500 \mathrm{kN}$ Stanat TA 315 rolling mill to a thickness of $0.87 \mathrm{~mm}$ while no change in width could be measured using a Vernier Caliper. The rolled strips were then loaded in uniaxial tension using the Amsler universal testing machine. The necking strains were determined as for the uniaxial tension experiments. A specimen after fracture can be seen in Figure 6c.

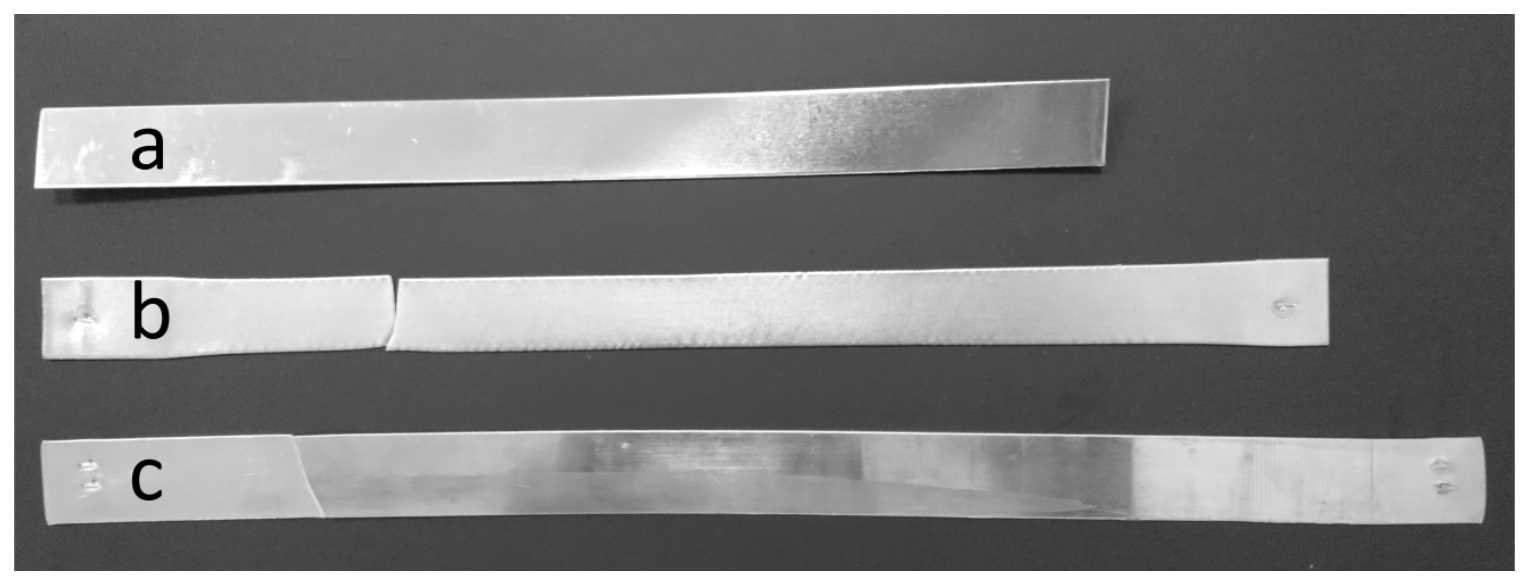

Figure 6. a) Strip before deformation, b) strip after uniaxial tension, c) strip after rolling and uniaxial tension.

Biaxial stretching followed by uniaxial tension

An in-house built Marciniak test equipment was utilized for the biaxial stretching. It consists of two octagonal blanks with edge lengths of approximately $10 \mathrm{~cm}$ (or $250 \mathrm{~mm}$ between parallel edges) placed on top of each other. One of the blanks has a center hole with a diameter of $51 \mathrm{~mm}$. Both blanks were clamped using a drawbead with a diameter of $214 \mathrm{~mm}$, thus preventing drawing-in of material during stretching. A punch with an outer diameter of $134 \mathrm{~mm}$ and a center hole with a diameter of $90 \mathrm{~mm}$ where used to stretch the sheets by collaring. The experiments were performed using a 600kN Mohr\&Federhaff press.

In order to determine the applied strain, a square grid of $5 \mathrm{~mm}$ dimensions was etched onto the plate surface using the Universal Marking System, ME3000T. Prior to etching, the surface was cleaned in alcohol and kerosene. The grid was applied by placing a stencil on top on the plate surface. A felt cloth is placed on top of the stencil and soaked in a mild etchant ME5. An electrochemical reaction is initiated by having wires attached to the plate and a roller, which is drawn across the felt cloth. The dimensions of the grid after deformation were determined from grid images made by an Epson GT-15000 scanner with a resolution of 1200dpi. A new grid was applied before the second deformation step.

After stretching, small dog bone shaped tensile tests were cut by high speed milling using coolant to avoid heating of the samples. A drawing of the dog bone can be seen in Figure 7. 


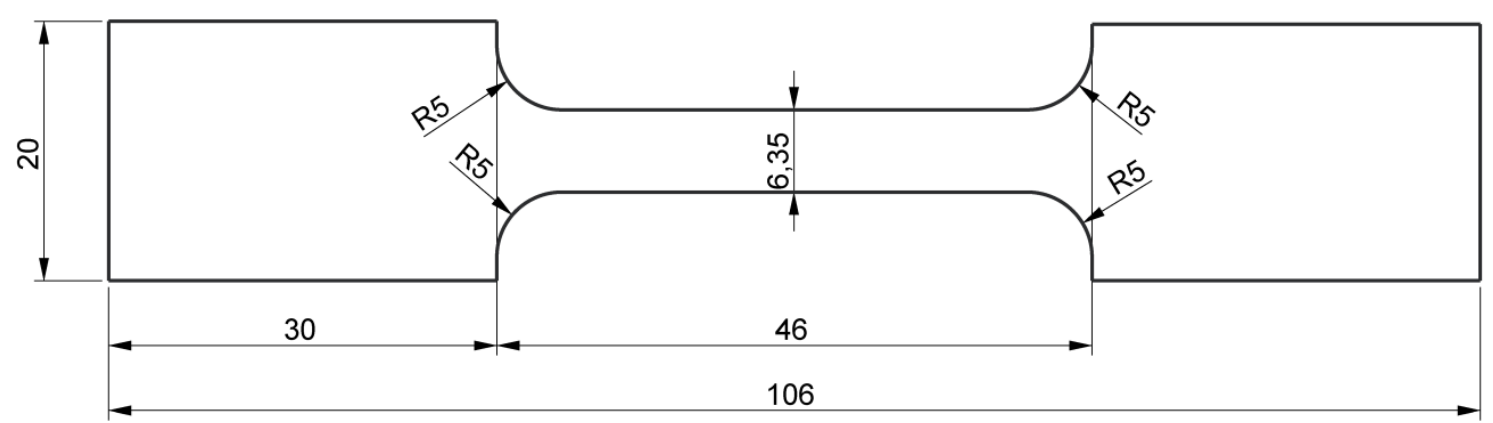

Figure 7. Dog bone dimensions.

Tensile experiments were conducted in a MTS Acumen pneumatic tensile tester with a maximum load cell capacity of $1 \mathrm{kN}$. A constant displacement rate of $0.5 \mathrm{~mm} / \mathrm{min}$ was employed. All samples were loaded to necking and all tensile tests were repeated three times. An example of an initial dog bone and a necked specimen can be seen in Figure 8.

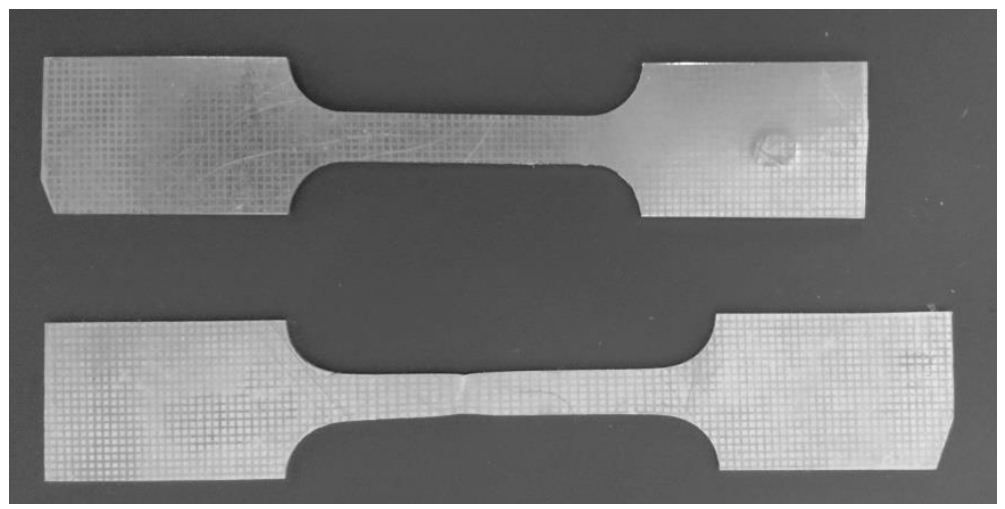

Figure 8. Dog bone before deformation and visibly necked specimen.

\section{Results and discussion}

The experimental strain paths and analytically computed forming limit curve can be seen in the "traditional" forming limit diagram in Figure 9. 


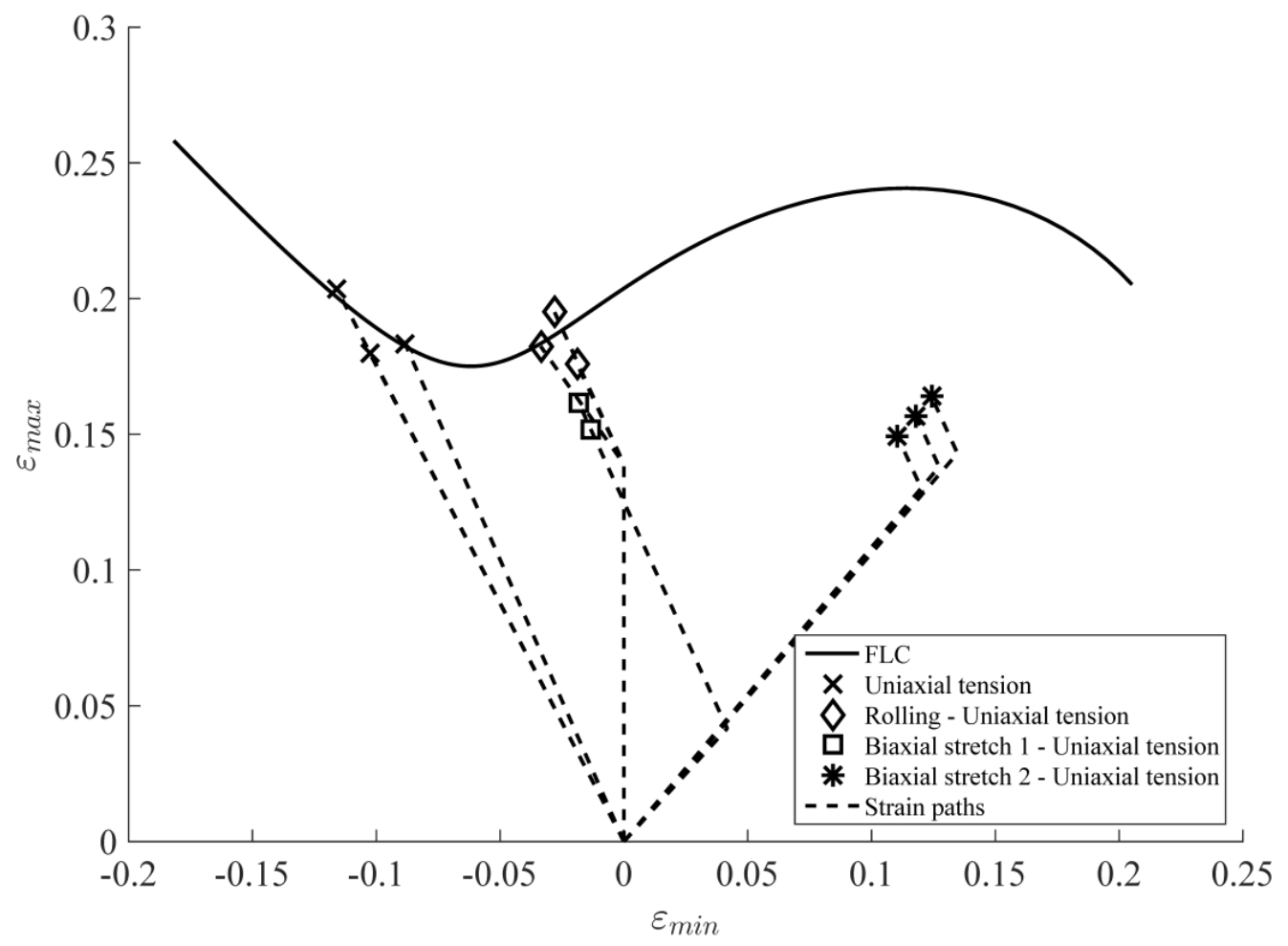

Figure 9. Forming limit diagram.

Figure 9 shows the computed forming limit curve, the experimentally determined strains at necking and the intermediate strains for the different strain paths. The uniaxial tensile tests lie close to the forming limit curve, which is logical since the forming limit curve is based on linear strain paths. The rolled-and-tensile-tested samples also lie on the forming limit curve, although the strain path is not linear. The two sets of experiments with first biaxial stretch and then uniaxial tension do not lie on the forming limit curve, hence demonstrating that a forming limit curve based on linear strain paths is not sufficient for nonlinear strain paths.

The presently suggested new forming limit diagram is calculated for the experiments and presented in Figure 10. 


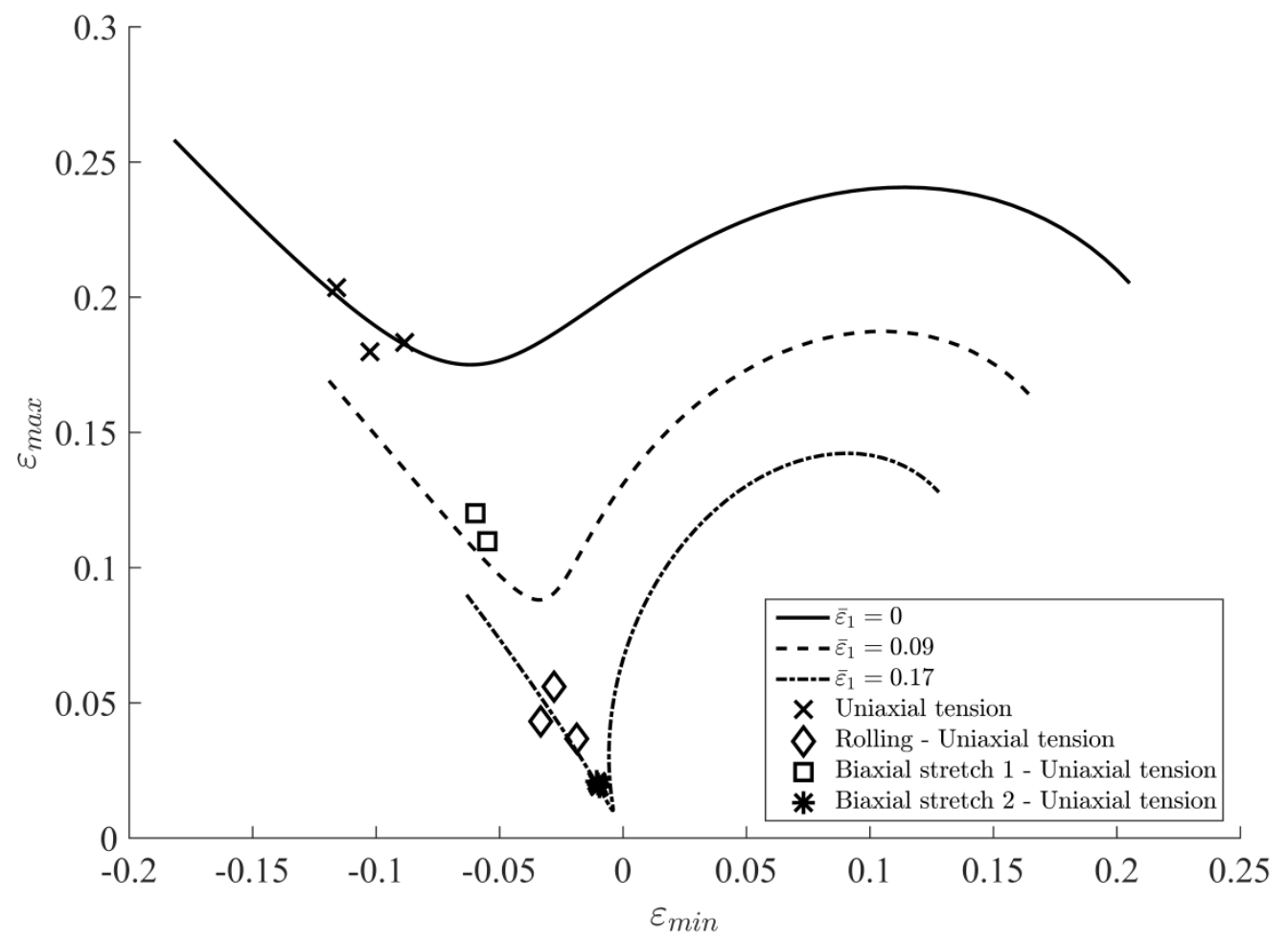

Figure 10. New formability diagram and experimentally found necking points corresponding to the equivalent strains $\bar{\varepsilon}_{1}$ obtained in the first forming operation.

Figure 10 shows predicted formability curves for equivalent plastic strains $\overline{\varepsilon_{1}}$ in the first forming operation of $0,0.09$ or 0.17 , corresponding to the first three experiments in Table 1. The markers indicate the experimentally determined onset of diffuse instability in the second forming operation. A formability curve is not drawn for the fourth experimental series with the largest biaxial strain since the equivalent strain of 0.29 is larger than the necking strain in uniaxial tension.

It can also be seen from Figure 10 that only a minor elongation (less than 0.02) could be performed before necking occurred for these specimens. The other three test series correspond well with the predicted formability curves at uniaxial tension. Further experiments are necessary to evaluate the performance of the new forming limit curve prediction in the stretching region. It should also be noticed that although only bilinear strain paths have been investigated, the procedure is also applicable to nonlinear strain paths in general since the remaining formability only depends on the equivalent strain and the final loading condition.

\section{Conclusion}

A new procedure for predicting forming limit curves for nonlinear strain paths has been suggested. The procedure is valid for diffuse necking. Experiments including uniaxial tension, plane strain compression and biaxial stretching followed by uniaxial tension until diffuse necking have shown good agreement with the suggested procedure. 


\section{Acknowledgment and Funding}

MRBJ and GW acknowledge support from the Danish Independent Research Council Technology and Productions Sciences grant n. DFF-13555-00220.

\section{Declaration of conflicting interests}

The authors declare no conflicts of interest.

\section{References}

1. Keeler J. Determination of forming limits in automotive stampings. Sheet Metal Ind 1965; 42: 683-691.

2. Goodwin GM. Application of strain analysis to sheet metal forming problems in press shop. La Metall Ital 1968; 60-68: 767-774.

3. Marciniak Z. Stability of plastic shells under tension with kinematic boundary condition. Archiwum Mechaniki Stosorwanej 1965; 17: 577-592.

4. Nakazima K, Kituma T. Forming limits under biaxial stretching of sheet metals. Testu-to Hagane 1967; 53: 455-458. In japanese.

5. ISO 12004-2:2008. Metallic materials -- Sheet and strip -- Determination of forming-limit curves -- Part 2: Determination of forming-limit curves in the laboratory. ISO 2008; 1: 1-27.

6. Müschenborn W and Sonne HM. Einfluss des Formänderungsweges auf die Grenzformänderungen des Feinbleches. Arch Eissenhüttenwes 1975; 46: 597-602. In german.

7. Yoon JW and Stoughton TB. Path independent polar effective plastic strain (PEPS) diagram for sheet forming. In: Weiland H., Rollett A.D., Cassada W.A. (eds) ICAA13 Pittsburgh. Springer, Cham 2012: 723-730. 
8. Arrieux R. Contribution to the determination of forming limit curves of titanium and aluminum. Proposal of an intrinsic criterion. PhD Thesis, INSA, Lyon, France, 1981. (In French).

9. Stoughton TB and Zhu X. Review of theoretical models of the strain-based FLD and their relevance to the stress-based FLD. Int J Plast 2004; 20: 1463-1486.

10. Stoughton TB and Yoon JW. A new approach for failure criterion or sheet metals. Int J. Plast 2011; 27: 440-459.

11. Upadhyua, MV, Capek, J, Petegem, SV, Lebensohn, RA and Swygenhoven, HV. Intergranular strain evolution during biaxial loading: A multiscale FE-FFT approach. JOM 2017; 69: 839-847.

12. Iadicola, MA, Hu, L, Rollett, AD and Foecke, T. Crystal plasticity analysis of constitutive behavior of 5754 aluminum sheet deformed along bi-linear strain paths. Int J Solids Struct. 2012; 49: 3507-3516.

13. Hill R. A theory of the yielding and plastic flow of anisotropic metals. Proc R Soc A 1948; 193: 281-297.

14. Swift HW. Plastic instability under plane stress. J Mechan Phys Solids 1952; 1: 118.

15. Lankford WT, Snyder SC and Bauscher JA. New criteria for predicting the press performance of deep drawing sheets. Trans Am Soc Met 1950; 42: 1197-1232.

16. Danckert J, Wanheim T. Determination of Instability in Sheet-Metal Based on the Anisotropic Yield Ellipse. Annals of the CIRP 1991; 40-1: 273-276. 